\title{
First nights, the adrenal axis, and steroids
}

\author{
Eric M. Graham, MD, ${ }^{\mathrm{a}}$ and Scott M. Bradley, $\mathrm{MD}^{\mathrm{b}}$
}

\footnotetext{
From the Divisions of ${ }^{\mathrm{a}}$ Pediatric Cardiology and ${ }^{\mathrm{b}}$ Pediatric Cardiac Surgery, Medical University of South Carolina, Charleston, SC.

Disclosures: Authors have nothing to disclose with regard to commercial support.

Received for publication Dec 1, 2016; accepted for publication Dec 6, 2016; available ahead of print January 25, 2017.

Address for reprints: Scott M. Bradley, MD, Division of Pediatric Cardiac Surgery, Medical University of South

Carolina, CSB 424, 96 Jonathan Lucas St, Charleston, SC 29425 (E-mail: bradlesm@ musc.edu).

J Thorac Cardiovasc Surg 2017;153:1164-6

$0022-5223 / \$ 36.00$

Copyright $(2016$ by The American Association for Thoracic Surgery

http://dx.doi.org/10.1016/j.jtcvs.2016.12.013
}

The scenario is familiar to all who care for patients undergoing congenital heart surgery: It is the first night after surgery and a neonate who has undergone a complex cardiac repair has low cardiac output unresponsive to volume and catecholamines. The first night was highlighted as a critical period by data from the Boston Circulatory Arrest Study, ${ }^{1}$ which showed a nadir in cardiac index at 9 to 12 hours after an arterial switch procedure. In the setting of catecholamine-resistant low cardiac output, there are limited therapeutic options available to avoid mechanical support. The use of exogenous glucocorticoids is one of these options. Perioperative steroid supplementation is aimed at blunting the inflammatory response to cardiopulmonary bypass (CPB), improving hemodynamic status and ultimately patient outcomes. The role of steroids in patients with congenital heart disease has been a subject of interest since the 1960s. Fifty years ago, Replogle and Gross $^{2}$ published a study in children and young adults undergoing cardiac operations with CPB in which 10 patients received perioperative dexamethasone ( 9 doses) compared with 10 control patients. They concluded that steroid administration resulted in possible lysosome stabilization, as evidenced by a reduction in $\beta$-glucuronidase after bypass. Although there were no data regarding clinical outcomes, the investigators noted "a better general appearance and state postoperatively in those patients who received dexamethasone.", 2

The hypothalamic-pituitary-adrenal axis responds to a variety of stimuli. ${ }^{3}$ The hypothalamus releases corticotropin-releasing hormone, which leads to the release of corticotropin (ACTH) by the pituitary. ACTH stimulates the synthesis and release of the primary effector glucocorticoid, cortisol, from the adrenal glands. Cortisol has myriad downstream effects important to the maintenance of homeostasis and the response to stress. Cortisol is approximately $90 \%$ bound to corticosteroid-binding globulin, and $5 \%$ to albumin, so that only $5 \%$ is present in the biologically active form, free cortisol. Adrenal responsiveness can be evaluated by the ACTH-stimulation test, which assesses the response of cortisol level to an exogenous dose of synthetic ACTH (cosyntropin).

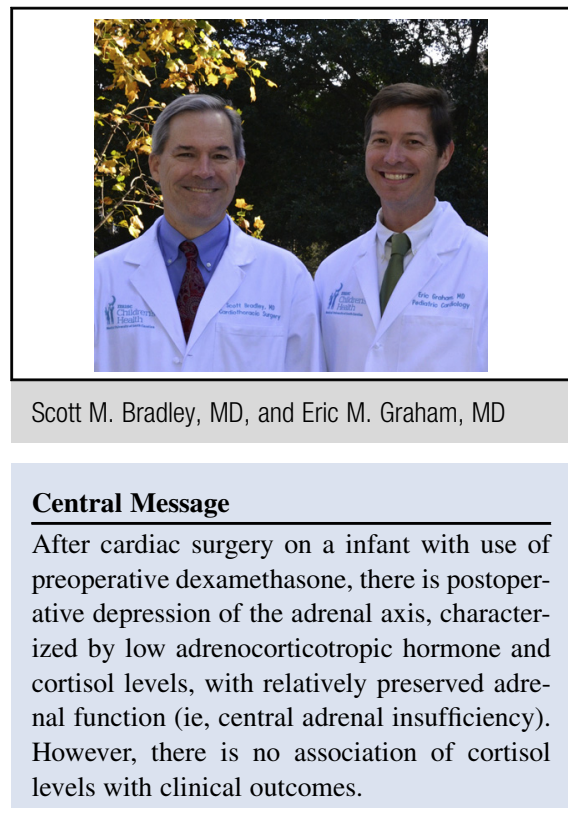

See Article page 1155 .

The past 15 years have seen numerous studies on the adrenal axis and the effects of steroids in patients with congenital heart disease. Several of the studies have been prospective, randomized controlled trials. ${ }^{4-8}$ Despite this, the role of perioperative steroids remains anything but clear, in part due to wide variations among the studies. The variations have included the study population (age and complexity), steroid regimen (prophylactic vs targeted), timing of administration (preoperative, anesthesia induction, CPB prime, and postoperative), as well as steroid type, dosing, and route. Further confusion results from the lack of accepted normal ranges for steroid levels in neonates, and of a clear definition of adrenal insufficiency in postoperative patients. There is also variation in the cosyntropin dose used in ACTHstimulation tests: the standard test uses 125 to $250 \mathrm{mcg}$, whereas a low-dose test uses $1 \mathrm{mcg}$. As a consequence, many questions in this area remain unanswered. These include the typical response of the adrenal axis to $\mathrm{CPB}$ in infants, and whether there exists a blood test or assay that can identify patients who have adrenal insufficiency and might benefit from steroid supplementation.

Wald and colleagues ${ }^{9}$ from Lurie Children's Hospital and the Mayo Clinic examine the adrenal axis in 68 infants undergoing CPB. They report levels of total cortisol, free cortisol, corticosteroid-binding protein, and $\mathrm{ACTH}$ at 3 
time points (pre-CPB, intensive care unit arrival, and 24 hours postoperative). In addition, ACTH stimulation tests were performed at the 3 time points. The primary finding is that levels of cortisol (both total and free) as well as ACTH decreased significantly after CPB. The decreases were quite marked, with cortisol falling to $21 \%$ and ACTH to $12 \%$ of the preoperative values. The cortisol response to ACTH stimulation was normal in only $41 \%$ of patients before surgery, but was either maintained or improved during the postoperative period. A subnormal total cortisol response to ACTH stimulation was associated with greater fluid requirement and longer intensive care unit length of stay. However, absolute cortisol levels (total or free) did not correlate with any outcome measure.

This prospective, observational study is well executed and provides a comprehensive look at measures of adrenal function after CPB. The collaboration between 2 wellregarded centers not only increases the number of patients, but strengthens the findings because the results were similar at both centers (personal communication from the authors). No previous study has directly measured free cortisol levels in this setting. So the information on free cortisol levels is new, although it does not seem to add substantively to that provided by total cortisol levels. It is puzzling that only $41 \%$ of patients had a normal cortisol response to ACTH before surgery. As the authors note, this may be due to the use of a low dose ACTH $(1 \mathrm{mcg})$ stimulation test. A reasonable interpretation of the data is that these patients had fairly profound postoperative depression of their adrenal axes, characterized by low ACTH and cortisol levels, with relatively preserved adrenal function (central adrenal insufficiency). Nonetheless, there was no clear association of adrenal insufficiency with clinical outcomes, at least on average. This leaves open the possibility that low postoperative levels of cortisol might impair outcomes in individual patients.

The major caveat to this study is that all of the patients received $1 \mathrm{mg} / \mathrm{kg}$ dexamethasone before CPB. This makes it impossible to determine whether the postoperative adrenal depression observed was due to the effects of CPB, or to the preoperative dexamethasone. In support of the latter, a previous study examining postoperative cortisol levels with no preoperative steroid exposure found that both cortisol and ACTH levels increased after CPB. ${ }^{10}$ Other studies with preoperative steroid dosing found depression in post-CPB cortisol levels similar to the current study. ${ }^{5,11,12}$ A previous study from the Mayo authors ${ }^{13}$ measured postoperative dexamethasone levels in patients who had received $1 \mathrm{mg} / \mathrm{kg}$ dexamethasone before CPB. Postoperative dexamethasone levels varied, but remained elevated out to 24 hours. Patients with high postoperative dexamethasone levels had very low cortisol levels, which persisted even after the dexamethasone levels fell to near zero. ${ }^{13}$ This suggests that depression of intrinsic cortisol levels extends beyond 24 hours after just a single dose of preoperative dexamethasone. It would be of great interest to see the current study repeated in patients with no preoperative steroid exposure. Limiting the patients to neonates undergoing more complex operations, and including postoperative indicators of cardiac output such as mixed venous oxygen saturation and near-infrared spectroscopy could maximize the chances of identifying a subset of patients who would predictably benefit from steroid therapy.

\section{CONCLUSIONS}

We offer the following observations:

1. Steroids administered in a variety of fashions result in a reduction in perioperative inflammatory markers. Their influence on meaningful clinical outcomes is less clear.

2. Preoperative prophylactic steroids do not appear to significantly improve outcomes, and can increase morbidity (eg, infection, renal function, and hyperglycemia). ${ }^{6,714-17}$ A National Heart, Lung, and Blood Institute-funded multicenter randomized controlled trial comparing prophylactic methylprednisolone to placebo in neonates undergoing cardiac operations with $\mathrm{CPB}$ is underway (ClinicalTrials.gov identifier: NCT01579513).

3. In patients with postoperative catecholamine-resistant hypotension, rescue steroid therapy can be effective, regardless of cortisol levels. ${ }^{18,19}$ Targeted steroid use will undoubtedly continue in this situation.

4. A blood test or assay to identify patients who might benefit from prophylactic or targeted steroid supplementation remains elusive.

\section{References}

1. Wernovsky G, Wypij D, Jonas RA, Mayer JE Jr, Hanley FL, Hickey PR, et al Postoperative course and hemodynamic profile after the arterial switch operation in neonates and infants. Circulation. 1995;92:2226-35.

2. Replogle RL, Gazzaniga AB, Gross RE. Use of corticosteroids during cardiopulmonary bypass: possible lysosome stabilization. Circulation. 1966;33:I86-92.

3. Cooper MS, Stewart PM. Corticosteroid insufficiency in acutely ill patients. $N$ Engl J Med. 2003;348:727-34.

4. Schroeder VA, Pearl JM, Schwartz SM, Shanley TP, Manning PB, Nelson DP Combined steroid treatment for congenital heart surgery improves oxygen delivery and reduces postbypass inflammatory mediator expression. Circulation. 2003; 107:2823-8.

5. Ando M, Park I, Wada N, Takahashi Y. Steroid supplementation: a legitimate pharmacotherapy after neonatal open heart surgery. Ann Thorac Surg. 2005; 80:1672-8.

6. Graham EM, Atz AM, Butts RJ, Baker NL, Zyblewski SC, Deardorff RL, et al. Standardized preoperative corticosteroid treatment in neonates undergoing cardiac surgery: results from a randomized trial. J Thorac Cardiovasc Surg. 2011; 142:1523-9.

7. Keski-Nisula J, Pesonen E, Olkkola KT, Peltola K, Neuvonen PJ, Tuominen N, et al. Methylprednisolone in neonatal cardiac surgery: reduced inflammation without improved clinical outcome. Ann Thorac Surg. 2013;95: 2126-32.

8. Robert SM, Borasino S, Dabal RJ, Cleveland DC, Hock KM, Alten JA. Postoperative hydrocortisone infusion reduces the prevalence of low cardiac output syndrome after neonatal cardiopulmonary bypass. Pediatr Crit Care Med. 2015;16: 629-36. 
9. Wald EL, Backer C, Dearani J, Li Z, Oliver WC, Crow SS. Total and free cortisol responses and their relation to outcomes after cardiopulmonary bypass in infants. J Thorac Cardiovasc Surg. 2017;153:1155-63.

10. Gajarski RJ, Stefanelli CB, Graziano JN, Kaciroti N, Charpie JR, Vazquez D. Adrenocortical response in infants undergoing cardiac surgery with cardiopulmonary bypass and circulatory arrest. Pediatr Crit Care Med. 2010;11:44-51.

11. Wald EL, Preze E, Eickhoff JC, Backer CL. The effect of cardiopulmonary bypass on the hypothalamic-pituitary-adrenal axis in children. Pediatr Crit Care Med. 2011;12:190-6.

12. Mackie AS, Gauvreau K, Booth KL, Newburger JW, Laussen PC, Roth SJ. Hemodynamic correlates of serum cortisol in neonates after cardiopulmonary bypass. Pediatr Crit Care Med. 2011;12:297-303.

13. Crow SS, Oliver WC, Kiefer JA, Snyder MR, Dearani JA, Li Z, et al. Dexamethasone levels predict cortisol response after infant cardiopulmonary bypass. $J$ Thorac Cardiovasc Surg. 2014;147:475-82.

14. Pasquali SK, Hall M, Li JS, Peterson ED, Jaggers J, Lodge AJ, et al. Corticosteroids and outcome in children undergoing congenital heart surgery. Circulation. 2010;122:2123-30.
15. Pasquali SK, Li JS, He X, Jacobs ML, O’Brien SM, Hall M, et al. Perioperative methylprednisolone and outcome in neonates undergoing heart surgery. Pediatrics. 2012;129:e385-91.

16. Mastropietro CW, Barrett R, Davalos MC, Zidan M, Valentine KM, Dellus RE. Cumulative corticosteroid exposure and infection risk after complex pediatric cardiac surgery. Ann Thorac Surg. 2013;95:2133-9.

17. Elhoff JJ, Chowdhury SM, Zyblewski SC, Atz AM, Bradley SM, Graham EM. Intraoperative steroid use and outcomes following the Norwood procedure: an analysis of the Pediatric Heart Network's public database. Pediatr Crit Care Med. 2016;17:30-5.

18. Shore S, Nelson DP, Pearl JM, Manning PB, Wong H, Shanley TP, et al. Usefulness of corticosteroid therapy in decreasing epinephrine requirements in critically ill infants with congenital heart disease. Am J Cardiol. 2001; 88:591-4.

19. Suominen PK, Dickerson HA, Moffett BS, Ranta SO, Mott AR, Price JF, et al. Hemodynamic effects of rescue protocol hydrocortisone in neonates with low cardiac output syndrome after cardiac surgery. Pediatr Crit Care Med. 2005;6: $655-9$. 